\title{
About the authors
}

Dr. Marlous Agterberg is Research and Valorization Manager at the KIN Center for Digital Innovation, Vrije Universiteit Amsterdam, the Netherlands. After having worked as researcher for ten years, she is in her current position responsible for creating social impact with the top academic research that is executed at KIN. She sets up new research collaborations with organizations and strives to bring academia and business closer together.

Marleen Huysman is Professor of Knowledge and Organizations and the Director of the KIN Center for Digital Innovation, Vrije Universiteit Amsterdam, the Netherlands. Her research relates to the development and use of digital technology in practice and has been published in international top-tier academic journals and books. She is a frequent academic and professional speaker. Marleen is author of the book Sharing Knowledge in Practice.

Lauren Waardenburg is Assistant Professor of Management Information Systems at IESEG School of Management, Lille, France. She conducted her $\mathrm{PhD}$ at the KIN Center for Digital Innovation. Her research is focused on how algorithmic technologies are changing the future of work. She conducted ethnographic research across a period of three years into the use of AI in the Dutch Police Force. 